\title{
TRAVESTIS VIVENDO COM HIV/AIDS E SEUS DETERMINANTES SOCIAIS: ANTES E DEPOIS DO DIAGNÓSTICO
}

\author{
ANGRA DIAS DA SILVA TAGLIATE
}

https://orcid.org/0000-0002-5891-6201

Departamento DST/AIDS de Juiz de Fora

\section{NEIL FRANCO}

https://orcid.org/0000-0002-1276-8901

Universidade Federal de Juiz de Fora

Este estudo versa sobre as histórias de vida de duas travestis que vivem com HIV/AIDS e que são acompanhadas pelo Serviço de Assistência Especializada (SAE), setor integrado ao Departamento DST/ AIDS vinculado à Secretaria de Saúde da Prefeitura de Juiz de Fora. 0 objetivo foi de conhecer seus determinantes sociais, seja no âmbito familiar, econômico, escolar, saúde, entre outros, de modo a identificar a construção do sujeito a partir da vivência e pertencimento a tantos demarcadores de exclusão do humano. Metodologicamente, é um estudo de abordagem qualitativa, construída a partir da correlação de fontes bibliográficas, documentais e empíricas. Para a construção das fontes empíricas utilizamos da história oral temática. Assim como outros estudos na área, evidenciamos o quanto essa população sofre com os diferentes tipos de preconceitos, seja pela proximidade com o universo da prostituição, seja por viver com HIV/ AIDS ou pelo fato de serem travestis. Por outro lado, o estudo nos permite afirmar o quanto o serviço de saúde com uma equipe motivada em trabalhar com um olhar mais humano faz a diferença para os/as usuário/as em acompanhamento, assim, partindo do relato das entrevistadas, o SAE/Juiz de Fora emerge como um espaço de respeito às diferenças e a diversidade humana.

Palavras-chave: História Oral. Travestis. Família. Prostituição. HIV/ AIDS. 


\section{ITS SOCIAL DETERMINANTS: BEFORE AND AFTER DIAGNOSIS}

This study is about two transvestite's life story. They both live with HIV/AIDS and are accompanied by the Specialized Assistance Service (SAE), a sector integrated with the STD / AIDS Department linked to the Juiz de Fora City Health Department. The goal was to know its social determinants, whether in the family, economic, school, health, among others and to understand the construction of the subject from the experience and belonging to so many demarcations of human exclusion. Methodologically it is a study of qualitative approach built from the collaboration of bibliography, documents and empirical sources. For the construction of empirical sources, we used thematic oral story. Just like other studies in the subject, we could have some evidences of how the population of transvestites suffers with all kinds of prejudices either for the proximity with the prostitution universe, living with HIV/AIDS or for the fact that they are transvestites. On the other hand the study allows us to state how the health service with a team motivated to work with a more humane look, knowing that HIV is not an easy disease to live with, makes a big difference to the patient or patients through the process, with all that coming from the respondents report, the SAE of Juiz de Fora emerges as a space of respect to the human differences and diversity.

Keywords: Oral History. Transvestites. Family. Prostitution. HIV/AIDS.

RESUMEN TRAVESTIS VIVENDO CON VIH/SIDA Y SUS

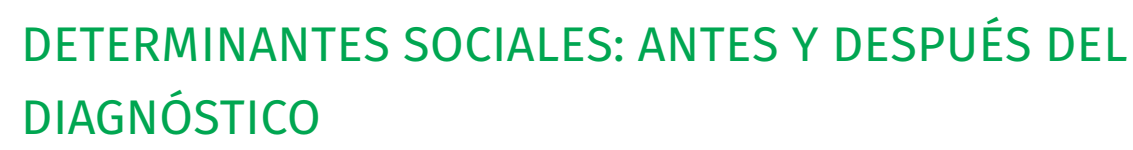

Este estudio trata sobre las historias de vida de dos travestis que viven con VIH/SIDA y que están acompañadas por el Servicio de Asistencia Especializada (SAE), un área integrada al Departamento de ETS/SIDA vinculada a la Secretaria de Salud de la prefectura de la Ciudad de Juiz de Fora. El objetivo fue conocer sus determinantes sociales, ya sea en la familia, la economía, la escuela, la salud, entre otros, a manera de identificar la construcción del tema a partir de la vivenvia y pertenencia a tantos marcadores de exclusión humana. Metodológicamente, es un estudio cualitativo basado en la correlación de fuentes bibliográficas, documentales y empíricas. Para la construcción de las fuentes empíricas utilizamos la historia oral temática. Al igual que otros estudios en el área, mostramos cuánto sufre esta población de diferentes tipos de prejuicios, ya sea por la 
proximidad al universo de la prostitución, por vivir con VIH/SIDA o por ser travestis. Por otro lado, el estudio nos permite afirmar en qué medida el servicio de salud con un equipo motivado para trabajar con un aspecto más humano hace la diferencia para los/as usuarios/ as en el acompañamiento, por lo tanto, a partir de los relatos de las entrevistadas, el SAE/Juiz de Fora surge como un espacio de respeto por las diferencias y de la diversidad humana.

Palavras claves: Historia oral. Travestis. Familia. Prostitución. VIH/ SIDA.

\section{Introdução}

0 presente estudo tem como motivação minha trajetória profissional no Departamento de Doenças Sexualmente Transmissiveis (DST/ AIDS) de Juiz de Fora, uma vez que, ao longo desses quinze anos de trabalho, tenho acompanhado na instituição o cotidiano de travestis que realizam o tratamento para o vírus HIV/ AIDS. Atrelado a este contexto está o interesse de atribuir significado a este público que, historicamente, esteve (e permanece) à margem da sociedade, uma vez que possuem corpos contraditórios no que se referem aos processos hegemônicos sociais e culturais da construção do gênero e vivências da sexualidade. Segundo vários/as autores/as, ao mesmo tempo em que são objeto de desejo por alguns/algumas, são vistos como seres abjetos (PERES, 2004; PELÚCIO, 2007; KULICK, 2008). Sobre a população evidenciada neste estudo, ainda possuem um agravante a mais: vivem com HIV/ AIDS.

Nessa perspectiva, Richard Miskollci (2012) descreve que o abjeto em termos sociais constitui a experiência de ser temido e recusado com repugnância, pois sua própria existência ameaça numa visão homogênea e estável do que é a comunidade interpretada como padrão, verdadeira, possível. Retomando os primeiros momentos da epidemia da AIDS no mundo e no Brasil, o autor situa que o/a "aidético/a", identidade do doente de AIDS na déca- da de 1980, encarnava esse fantasma ameaçador contra o qual a coletividade expunha seu código moral.

Partindo dessas argumentações, tem-se como proposta trabalhar com a história de vida de travestis que vivem com HIV/AIDS e conhecer seus determinantes sociais, seja no âmbito familiar, econômico, escolar, da saúde, entre outros. Enfim, refletir sobre a construção do sujeito a partir da vivência e pertencimento a tantos demarcadores de exclusão do humano.

Importante destacar o significado de algumas terminologias que estarão presentes no decorrer deste trabalho, tais como: travestis, transexuais e transgêneros (TTTs). Como referência a abordagem realizada por William $\mathrm{Pe}-$ res $(2009$, p. 236) sobre o universo existencial desses sujeitos:

De modo bastante rápido, defino as travestis como pessoas que se identificam com a imagem e o estilo feminino, apropriando-se de indumentárias e adereços de sua estética, realizando com frequência a transformação de seus corpos, quer por meio da ingestão de hormônios, quer através da aplicação de silicone industrial e das cirurgias de correção estética e de próteses. As transexuais são pessoas com demandas de cirurgias de mudança de sexo e de identidade civil, demandas que não encontramos nas reivindicações emancipatórias das travestis. Já as transgêneros são pessoas que se caracterizam esteticamente por orientação do gênero oposto, não se mantendo o tempo todo 
nesta caracterização, como o fazem as travestis e as transexuais. Como exemplos destas últimas podemos elencar as/os transformistas, as drags queens, os drag kings etc.

Vale destacar também que sexo, identidade de gênero e orientação sexual são categorias diferentes umas das outras. Quando nos referimos a sexo, ele é classificador do sujeito em termos de macho e fêmea, com referência aos órgãos genitais. Sobre a identidade de gênero, é como o sujeito se identifica e deseja ser identificado socialmente. Esta categoria classifica os sujeitos em cisgêneros como aqueles/ as que se identificam com o sexo determinado no seu nascimento e transgêneros aqueles/as que não se identificam com seu sexo biológico. A orientação sexual ou identidade sexual refere-se ao desejo e atração sexual por determinados gêneros, ou ainda, a nenhum deles. Nessa perspectiva, respectivamente, a pessoa pode ser identificada ou se identificar como heterossexual, homossexual, bissexual ou assexual (LOURO, 1997; BRASIL, 2019).

Como o foco desta pesquisa são as histórias de vida de travestis, é de extrema relevância resgatar o histórico da origem desta palavra. Jorge Leite Júnior (2008) descreve que em 1910 surge um dos principais estudos científicos sobre sexualidade e vestimentas: Die Transvestiten, traduzido para o inglês como Transvestites - the erotic drive to cross-dress, escrito por Magnus Hirschfeld 1 , conceituado médico e psicólogo alemão do período e um dos precursores da "sexologia". "Foi através deste estudo que originou os termos "traves-

1 Magnus Hirschfeld, médico, nasceu em 1868, gay e judeu que defendia LGBTs do nazismo. Hirschfeld não acreditava na binaridade do gênero ou da sexualidade, mas sim num leque amplo de identidades, registrando até 64 delas em sua pesquisa. Seu trabalho não era puramente teórico e, entre suas aplicações práticas, ele fez a primeira cirurgia moderna de readequação sexual, sendo um pioneiro nesse campo. Devido à sua especialização, era apelidado de "Einstein do sexo", um título ao qual respondia com "Einstein é o Hirschfeld da física" (LEITE JUNIOR, 2008). ti" e travestismo", que foi associando o uso de roupas do sexo "oposto" a um sentido sexual (LEITE JÚNIOR, 2008).

Segundo o autor, "travesti" (transvestite) vem dos termos em latim trans, que significa através e vestitus, com o sentido de estar vestido, e travestismo (transvestism) de trans e vestis, igual à roupa. Nessa direção, Leite Júnior (2008) aponta que Magnus Hirschfeld apresentou como inovação o termo e o conceito de "travestismo", criando uma categoria clínica nova, como todos os "ismos" forjados na época e associados à sexualidade e dando um novo sentido a palavra "travesti": uma pessoa (tra)vestida com roupas do sexo (gênero) oposto por motivações eróticas.

Estabelecendo aproximação com o enfoque deste estudo, no Brasil, inicialmente, havia uma relação do termo travesti com o meio artístico e a prostituição em razão das precariedades econômicas que artistas pobres vivenciavam. Ancorado nos estudos de Leite Junior (2008), Neil Franco (2014, p. 38) sustenta essa argumentação ao explicitar que:

A palavra travesti esteve inicialmente relacionada ao disfarçar-se e, consequentemente, ligada ao campo da arte, do entretenimento, mais especificamente, do teatro. Com isso, uma das justificativas para o estreito vínculo entre travesti e prostituição relacionou-se diretamente à concepção de artistas, principalmente de atrizes, vigente no contexto social brasileiro do início do século XX. Nesse período, essas pessoas eram vistas como prostitutas e vice-versa.

Desta forma, na abordagem deste artigo pretendemos debruçar, principalmente, sobre o universo trans ${ }^{2}$, com ênfase nas travestis, através das histórias vividas e expressadas por essas pessoas em seus cotidianos existenciais,

2 Marcos Benedetti (2005, p. 17) utiliza a expressão “universo trans" uma vez que considera esta terminologia mais ampla no que se refere às possibilidades de "transformações de gênero", abrangendo todas as personificações de gênero polivalente, modificado ou transformado, não somente pelas travestis. 
de forma a demarcar alguns processos de estigmatização e os modos de subjetivação. Processos de estigmatização são aqueles em que as pessoas, ao romperem com os modelos previamente dados pela normatização, ficam marcadas negativamente, depreciadas a ponto de serem desprovidas de direitos a ter direitos. A visão desses processos se dá através dos encontros diversos que mantemos no cotidiano do universo de travestis, transexuais e transgêneros. Os processos de estigmatização vividos por pessoas trans denotam toda a organização de suas subjetividades, construídas ao longo das relações que estabelecem com os/ as outros/as, com o mundo e consigo mesmas (PERES, 2009).

A maneira como as travestis são vistas socialmente as expõem a várias situações que configuram a exclusão de direitos. Segundo Peres (2004), neste processo de exclusão estão inseridos a exclusão familiar, social, econômica, sexual, cultural, religiosa, escolar, etc. Quando se atrela este processo de travestilidade ao fato de viverem com HIV/AIDS, a exclusão se torna ainda mais enfática. Diante deste contexto, Peres (2004, p. 28) aponta que: “A composição existencial na vida dessas pessoas, em rede de exclusão, favorece a efetivação do que já dominamos 'violência estrutural'3 , e coloca as pessoas mais intensamente disponibilizadas aos riscos e vulnerabilidades do HIV/AIDS, de forma muito perversa".

Ao falar das vulnerabilidades no que se refere ao universo das travestis frente ao HIV/ AIDS, e outras Infecções Sexualmente Trans-

3 O conceito de violência estrutural, portanto, torna evidente que a ideia de risco individual deve ser extrapolada. O grande avanço, em termos de teorização da prevenção dos últimos anos é o processo de mudança do conceito de risco comportamental para o conceito de vulnerabilidade social. Entretanto, o desenvolvimento desses conceitos nos obriga a modificar também uma grande parte do trabalho que fazemos. Inicialmente, é preciso deixar de ter uma preocupação tão centrada na informação e na intervenção comportamental, e fomentar o que Peres (2004) define fundamentalmente de intervenção estrutural. missiveis (IST), são categoricamente estabelecidas relações a condições sociais, permeadas pela miséria e pobreza, violência, prostituição e uso de álcool e drogas. Grande parte das travestis no Brasil é excluída da família e da escola ainda muito jovens, restando-lhes as ruas como único espaço possível de sobrevivência, lazer e socialização. Sem formação, são repudiadas do mercado de trabalho, muitas vezes encontrando na prostituição a única forma de sobrevivência (FERREIRA JUNIOR; FRANCISCO; NOGUEIRA, 2016).

Como forma de amparo perante o Sistema de Saúde, o Ministério da Saúde, através da Política Nacional de Saúde Integral de Lésbicas, Gays, Bissexuais, Travestis e Transexuais, aponta que:

Ao surgir a epidemia HIV/Aids, no início dos anos 80, à época fortemente relacionada aos gays, o governo brasileiro apoiou mobilizações da população homossexual masculina na prevenção da doença. Essas mobilizações surtiram grande efeito sanitário diante da amplitude do número de casos que acometeu esse grupo. 0 movimento, então constituído majoritariamente por homens, gradualmente foi incorporando grupos com outras identidades sexuais e de gênero, particularmente as lésbicas e travestis. As demandas desses grupos ampliaram a discussão e, consequentemente, redirecionaram as estratégias da prevenção e do cuidado das pessoas em relação ao HIV/Aids (BRASIL, 2013, p. 09).

No trajeto dessas iniciativas governamentais, o Departamento DST/AIDS de Juiz de Fora, inaugurou o Serviço de Assistência Especializado (SAE) no ano de 1996 e, desde então, as travestis que vivem com HIV/AIDS realizam o acompanhamento no serviço, assim como outras pessoas da comunidade.

Desta forma, no que se refere ao amparo pelo sistema de saúde no Brasil, as travestis que vivem com o vírus HIV e/ou são doentes de AIDS, através das reivindicações realizadas em parceria do Programa Nacional - IST/AIDS 
do Ministério da Saúde junto às Organizações Não Governamentais (ONGS), no enfretamento e discussão com os laboratórios e as leis de patentes, têm obtido algumas vitórias que permitem uma pequena melhoria na qualidade de vida dessas pessoas (PERES, 2004).

Atualmente, essas medidas são descritas no Plano de Enfrentamento da Aids entre Gays, Homens que fazem Sexo com Homens (HSH) e Travestis, de 2007, por meio da Agenda Afirmativa Travestis na qual aponta como objetivos específicos:

1 - Garantir prioridade nas três esferas de gestão para ações de enfrentamento das DST/aids voltadas às travestis, do ponto de vista técnico, político e financeiro.

2. Ampliar a abrangência geográfica e a qualidade das ações de prevenção, assistência e tratamento do HIV, das DST e hepatites, para travestis, considerando novas tecnologias de educação em saúde e demandas e especificidades desse grupo populacional.

3. Promover a visibilidade positiva das travestis junto às instâncias governamentais, serviços de saúde e população em geral para reduzir as vulnerabilidades que deixam esse grupo mais suscetivel à infecção pelo HIV e pelas DST.

4. Promover e ampliar a intersetorialidade das ações voltadas para a redução das vulnerabilidades às DST/aids das travestis.

5. Produzir conhecimento sobre representatividade na população brasileira, participação na epidemia de aids, características e vulnerabilidades socioculturais e econômicas e práticas das travestis frente à infecção pelas DST e pelo HIV.

6. Garantir o monitoramento, avaliação e controle social deste Plano de Enfrentamento da Epidemia de Aids e outras DST e da Agenda Afirmativa para Travestis, considerando as três esferas de governo (BRASIL, 2007, p. 17).

Apesar de esforços cuja finalidade é atender esta parcela da população que é tão estigmatizada, Simone Monteiro, Mauro Brigadeiro e Regina Barbosa (2019) apontam que no campo da saúde, a vulnerabilidade de travestis e transexuais pode ser percebida por meio dos alarmantes índices de violência e assassinatos sofridos, lado a lado com as complicações relacionadas à saúde mental (por ex.: depressão, tentativa de suicídio) e por meio da alta prevalência do HIV.

Além disso, o estigma e a discriminação sexual têm sido apontados como importantes obstáculos ao acesso desse segmento social aos serviços de prevenção e cuidado. Em função disso, a agenda de direitos de cidadania para esse segmento social inclui ainda demandas por uma atenção integral em saúde e acesso aos serviços livre de discriminação. Essas reivindicações vêm sendo construídas paralelamente aos esforços por consolidação do Sistema Único de Saúde (SUS) e evocam debates acerca das implicações das desigualdades sociais no cuidado em saúde.

A partir dessas contextualizações apresentadas, definiu-se como questão problema deste estudo: delinear a história de vida de duas travestis que vivem com HIV/AIDS e que são acompanhadas pelo Serviço de Assistência Especializado (SAE), setor que está integrado ao Departamento DST/AIDS vinculado à Secretaria de Saúde da Prefeitura de Juiz de Fora. Para responder a tal questão, apresentaremos a seguir o detalhamento metodológico; a descrição, análise e discussão das histórias de vidas das investigadas; nossas considerações a respeito e as referências.

\section{A construção das histórias: 0 trajeto metodológico}

Metodologicamente, ancoramo-nos em uma abordagem qualitativa construída a partir da correlação de fontes bibliográficas, documentais e empíricas. A pesquisa qualitativa, segundo Minayo (2009, p. 21): 
[...] responde a questões muito particulares. Ela se ocupa, nas Ciências Sociais, com um nível de realidade que não pode ou deveria ser quantificado. Ou seja, ela trabalha com o universo dos significados, dos motivos, das aspirações, das crenças, dos valores e das atitudes. Esse conjunto de fenômenos humanos é entendido aqui como parte da realidade social, pois o ser humano se distingue não só por agir, mas por pensar sobre o que faz e por interpretar suas ações dentro e a partir da realidade vivida e partilhada com seus semelhantes.

Para a construção das fontes empíricas utilizamos da história oral temática, uma vez que nos pautamos pela utilização de um roteiro de questões para a entrevista. No sentido mais amplo, José Meihy e Fabíola Holanda (2010, p. 15) explicam que a história oral "[...] é um conjunto de procedimentos que se inicia com a elaboração de um projeto e que continua com o estabelecimento de um grupo de pessoas a serem entrevistadas." O autor e a autora apontam ainda que: "História oral é um recurso moderno usado para a elaboração de registros, documentos, arquivamento e estudos referentes à experiência social de pessoas e de grupos. Ela é sempre uma história de tempo presente e também reconhecida como história viva." (MEIHY; HOLANDA, 2010, p. 17).

A proposta foi trabalhar com a história de vida de duas travestis que vivem com HIV/AIDS e que fazem acompanhamento no Serviço de Assistência Especializado (SAE). Utilizou-se como critério de seleção aquelas que tinham conhecimento do seu diagnóstico há mais tempo, assim foi possível traçar um paralelo de como se deu a vivência do antes e depois do diagnóstico.

0 procedimento utilizado foi entrevista que, segundo Meihy e Holanda (2010, p.14) pode ser entendida como "[...] uma fórmula programada e responde à existência de projetos que a justificam." A história oral temática foi o tipo investigativo adotado por oferecer maior objetividade em que a discussão se dispõe em torno de um assunto central definido, ou seja, a partir de um assunto específico e preestabelecido, busca-se o esclarecimento ou opinião do/a entrevistado/a sobre algum acontecimento definido.

Para realização dessas entrevistas, foi construído um Termo de Consentimento Livre e Esclarecido (TCLE) no qual consta a proposta do projeto e a garantia dos aspectos éticos que envolvem o estudo, dentre eles, o anonimato das participantes ${ }^{4}$. Com isso, foi proposto que as colaboradoras escolhessem um nome fictício que as representassem na redação deste trabalho. As entrevistas foram realizadas no mês de abril de 2019, numa sala cedida pelo Departamento DST/AIDS.

Utilizou-se o gravador de voz para obter o registro das entrevistas. Após este registro foi realizada a transcrição do oral para o escrito a fim de obter uma análise detalhada de cada história de vida. Como descreve o método em pauta, depois de transcritas, as entrevistas foram encaminhadas para as colaboradoras para que revisassem o material e, caso fosse necessário, pudessem fazer alterações no texto. Este foi o critério para que pudéssemos iniciar a análise do material (MEIHY; HOLANDA, 2010).

Com os resultados obtidos por este trabalho a pretensão é de divulgá-lo no meio acadêmico, assim como apresentá-lo para as protagonistas deste estudo e para os/as profissionais do Departamento DST/AIDS, confirmando que, segundo Meihy e Holanda (2010, p. 17), “[..] o compromisso com a 'devolução' dos resultados do projeto é condição básica para se justificar um projeto de história oral."

Diante do exposto, trabalhar com este tipo de abordagem possibilitou conhecer a história de vida dessas travestis, transformando-as em

4 Este termo foi formulado em duas vias, assinadas por ambas as partes, onde uma encontra-se com a pesquisadora e a outra com as entrevistadas. 
protagonistas das suas próprias vidas. Nisso, como sugere o método da história oral, as categorias de análises foram construídas a partir do material das entrevistas, norteando sobre quais aspectos deveriam ser mais evidenciados pelo estudo. Dentre eles, foi possivel elencar dimensões de compreensão das vidas das colaboradoras que emergiram como significativas para as discussões, quais sejam, a família, a escola, o trabalho, o sistema de saúde e o convívio social.

\section{Travestis, família, educação, trabalho, sistema de saúde e sociedade}

Como a proposta deste trabalho é abordar a história de vida de travestis que vivem com HIV/AIDS e conhecer seus determinantes sociais, no âmbito familiar, econômico, escolar, da saúde, entre outros, esta etapa será composta pela análise destes determinantes, possibilitando, desta forma, conhecer as particularidades de cada uma destas protagonistas.

A primeira protagonista se nomeou como Kely e estava com 57 anos de idade e vivia com HIV desde 2001. A segunda protagonista, que optou pelo nome Luana, estava com 46 anos e desde o ano de 2000 vivia com HIV. Ambas se identificaram como de cor parda e de religião católica, assim como, no período em que foram entrevistadas, em abril de 2019, encontravamse civilmente solteiras e residiam sozinhas em bairros periféricos da cidade de Juiz de Fora.

A afeição pelo gênero feminino e o desejo de situar neste universo é outro fator que aproxima as entrevistadas, não somente uma da outra, mas, da maioria das travestis de nossa sociedade. Dentro do universo de construção do feminino é possivel observar que o padrão de beleza de algumas travestis, por vezes, colocase como o objeto da percepção unânime que negligencia, porém, qualquer definição. Essa tentativa, por vezes satisfatória, seja clandestinamente ou com o aval da medicina, de possuir seios siliconados, quadris moldados, bumbuns apresentáveis, coxas torneadas e rostos refeitos se faz presente em suas vidas desde muito cedo (NOGUEIRA, 2012). Considerando os espaços e tecnologias disponiveis na época em que se constituíram travestis, Kely e Luana destacam sobre seus processos de transformação, em que ambas relatam sobre a utilização do hormônio feminino e, não diferente de diversas etnografias sobre essa população, a auto -hormonização é um aspecto recorrente:

O processo de transição do meu corpo, enquan-
to travesti, foi através do uso de hormônio. An-
tigamente era assim, hoje em dia tem médico,
eles veem dosagem de hormônio e tudo. An-
tigamente a gente tomava de cabeça: injeção,
comprimido de anticoncepcional, tomava da
cabeça, e aí deu por ter dado. Mas, hoje em dia
é tudo controlado, naquela época você nem po-
dia procurar médico que eles nem te atendiam
(Kely, abril, 2019).

O processo de construção do feminino marcado pelo fascínio por roupas, jogos e cores vinculados ao outro gênero e, que para a maioria das travestis são proibidos na infância, podendo ser identificado como desencadeador dos conflitos iniciais (BENTO, 2006, p. 164), foi um aspecto relatado por Kely e Luana, entretanto, como veremos na próxima seção, Luana sofreu de forma mais incisiva as consequências deste processo que a levou a abandonar o lar muito cedo. Sua construção do feminino foi efetivada fora do âmbito familiar.

O hormônio diminuiu o pelo do meu corpo, e me deu seios. Eu sempre tomei o hormônio por conta própria, eu tomava anticoncepcional por conta própria. Eu tinha uma amiga travesti que se chamava $R$, ela morreu, ela era tipo minha madrinha. Ela falava que não era para tomar a injeção, mas eu comecei a tomar e deu certo. Eu senti a mudança no meu corpo. Nunca fiz plástica nem nada (Luana, abril, 2019). 
Em consonância com Pelúcio (2007), Luana confirma que, às vezes, na casa dos pais, as travestis já se "montam", mas, a transformação de fato só ocorre fora do ambiente familiar. Muitas travestis saem de casa ainda "gayzinhos", classificação êmica que indica que ela já assumiu a orientação sexual para a sociedade, mas ainda não usa roupas femininas ou faz uso de hormônios. Na verdade, para muitas, em especial no período em que as colaboradoras construíram seu gênero, anterior a uma real identificação e constituição do feminino, o único caminho para mulheres trans era transitar pela identidade sexual homossexual (FRANCO, 2014).

Nas próximas seções aprofundaremos na história de vida das protagonistas deste trabalho no que tange sobre a família, escola, trabalho, sistema de saúde, HIV/AIDS e suas perspectivas de vida.

\section{A construção do feminino e suas interfaces com família, escola e o trabalho}

A respeito do processo de se descobrir travesti, tanto Kely quanto Luana afirmaram que sempre sentiam que o seu sexo biológico não era o que lhes pertencia:

Descobri-me enquanto travesti desde pequena, gostava mais de brincar com as minhas primas, gostava tudo mais para as coisas de menina, de casinha, boneca. E aí, depois, a gente começa a namorar menino. Não me via quando falavam: "Ah, tem que namorar menina." Desde novo a gente percebe! (Kely, abril, 2019).

Não diferente de Kely, Luana conta de uma precocidade na identificação que se deu na incompatibilidade entre sexo genital e o gênero com o qual se compreendia, o que desencadeava conflitos familiares.

Eu, desde criança, já vestia roupa da minha mãe, já colocava salto da minha mãe. Eu sofri muito com esta mudança, quando me revelei como travesti. Minha mãe sempre aceitou, a mãe sempre aceita o filho do jeito que é, mas, o meu pai, eu acho que ele engoliu, depois ele foi aceitar, quando ele viu que não dava pra me controlar mais, porque eu mesma fazia o meu sustento. Quando eu estava debaixo do sustento dele, ele queria que eu fosse o [Nome Masculino de Registro], mas nunca quis ser o [Nome Masculino de Registro], eu sempre quis ser a Luana (Luana, abril 2019).

As travestis vivenciam situações de opressão e discriminação desde quando suas escolhas e mudanças corporais começam a se tornar conhecidas. A descoberta da afinidade como o gênero que não é coerente com o sexo genital identificado ao nascimento é o momento no qual convivem com surras, insultos e diversos tipos de rejeição familiar (SOUZA et al., 2015); aspecto vivenciado de forma mais latente por Luana:

Eu desde criança já vestia roupa da minha mãe, já colocava salto da minha mãe, aí meu pai chegava do serviço e me batia. Minha mãe não me batia, mas meu pai sempre me batia, me surrava. Então, eu, com 11 anos, resolvi ir embora, porque eu apanhava muito, e muito. (Luana, abril 2019).

Não estar nos padrões de gênero esperados pela família é um dos primeiros obstáculos vivenciados pelas travestis (SOUZA, 2015). Da mesma forma, a dificil compreensão sobre os limites do que seriam manifestações de sexualidade e a construção do gênero de uma criança gera conflitos no eixo familiar, assim como descrito pelas entrevistas e reafirmado por Larissa Pelúcio (2007, p. 282) ao explicar que "a 'suspeita' familiar volta-se logo, para a sexualidade, erotizando esse desejo de ser/ parecer feminino do garoto. Não incomum que as travestis relatem que, desde a infância, elas também associavam esse interesse ao desejo por meninos e homens."

Esta incompatibilidade entre sexo e gêne- 
ro que se manifesta desde muito cedo é uma situação de vida que a maioria das pessoas trans passa de alguma forma, assim, em muitos casos:

O primeiro passo rumo à construção da pessoa travesti vem, na maioria das vezes, com a saída de casa. Existem casos, também comuns, em que ainda na infância a travesti foge, ou é expulsa. Esse deslocamento para fora de casa materna/paterna tem sempre relação com a aparente incongruência do comportamento esperado para uma menino (PELÚCIO, 2007, p. 282).

A argumentação de Pelúcio (2007) é confirmada por Luana: "Meu pai me batia muito, aí com 11 anos eu fugi e fui me prostituir. Com 15 anos eu voltei e eles me aceitaram, eu fui sozinha, pedindo carona pela BR. E lá me prostituí, para me sobreviver, para não passar fome." (Luana, abril 2019).

Diferente da realidade que Luana vivenciou, da não aceitação do pai, Kely relata outra versão da sua família quando descobriu que ela era travesti.

Eu dividi meu momento de mudança para travesti com uma tia, hoje ela já é falecida, ela toda vida foi assim... bem liberal. Ela notava isso em mim. É igual pai e mãe, a minha mãe depois me falou que sempre notou, mas ela não falava. Meu pai me aceitou primeiro do que minha mãe e é difícil. Não é? (Kely, abril 2019).

Se comparado ao estudo de Franco (2014), é possivel perceber uma similaridade neste processo de aceitação e acolhimento da família com os relatos de três das docentes (Adriana Sales, Adry e Geanne) entrevistadas pelo autor. Como exemplo, Geanne relatou o relacionamento sem conflitos com a família durante e após o processo de transformação, atribuindo à autoridade de sua mãe que sempre a protegeu, o motivo de não ter vivenciado recusas no ciclo familiar.

Considerando essas reações como exceções no que se refere à construção de iden- tidades travestis no âmbito familiar (PERES, 2009; PELÚCIO, 2007). Os relatos de Kely e Luana levantam indícios de que nem todas as relações familiares se restringem a adotarem uma postura heteronormativa e excludente de travestis. Vários estudos indicam que outros espaços sociais, como a escola, parecem mais restritivos a essas construções do gênero.

Peres (2004) aponta que em suas escutas e observações etnográficas é frequente ouvir histórias de travestis que lamentam por não terem conseguido estudar, não poderem fazer faculdade e exercerem uma profissão na qual proporcionasse a sobrevivência, sem terem que recorrer à prostituição. As vivências das protagonistas deste estudo convergem com os apontamentos do autor, como se vê a seguir.

$\mathrm{Na}$ época que me tornei travesti eu ainda estudava, mas eu saí. Não conseguia mais estudar porque os meninos encarnavam, perturbavam. A gente não tinha sossego na sala de aula, a gente abandonava o estudo. Quase todos os travestis passam por isso. Hoje em dia você passa em frente a colégios, você vê até travestis estudando, todo mundo conversa com eles (Kely, abril 2019).

Além das dificuldades passadas dentro do contexto familiar, Luana ressalta os impasses dentro da escola que contribuíram para sua fuga desses espaços sociais:

Antigamente, na minha época, eu estou com 46 anos, não tinha como estudar, era muito trote. Hoje em dia tem como estudar, tem muito travesti que está até se formando. Eu não tive cabeça para estudar porque eu tive que fugir de casa (Luana, abril 2019).

A respeito desse processo, Junqueira (2009, p. 25) aponta que as experiências de deboche e humilhação, as diversas formas de opressão e os processos de exclusão, segregação e marginalização a que estão expostas travestis e transexuais constituem um quadro de "siner- 
gia de vulnerabilidades" que as arrasta como uma "rede de exclusão" na qual:

[...] vai se fortalecendo, na ausência de ações de enfrentamento ao estigma e ao preconceito, assim como de políticas públicas que contemplem suas necessidades básicas, como o direito de acesso aos estudos, à profissionalização e a bens e serviços de qualidade em saúde, habitação e segurança.

Um relato apresentado por Peres (2009) é bem similar ao depoimento de Luana. Ele aponta que uma travesti, pobre, candombleira, vivendo com HIV/AIDS, aos 42 anos, relatou um episódio ocorrido ainda em sua infância, quando cursava a quarta série primária. Ela ainda não era travesti e se portava como menino, mas devido aos trejeitos femininos sempre era molestada e agredida pelos outros meninos que a humilhavam constantemente. Um dia, após o sinal de retorno do recreio, ela dirigiu-se ao banheiro e foi atacada por nove meninos que a obrigaram a fazer sexo oral e anal com todos do grupo.

Quando eu ia ao banheiro que tinha que ser de homem, eu ficava presa no banheiro dos homens, eles praticamente me estupravam, (...), saía na hora do recreio, eles me levavam pro banheiro para me estuprar. Era forçado, era horrivel, mas não podia falar nada, tinha que tolerar, porque senão tolerasse, eu apanhava deles. Não podia contar para ninguém, eles falavam: "já que você gosta, você tem que fazer comigo." Ai eu fazia pra lá. Isso foi quando eu tinha 8 a 9 anos... Até os 10 anos eles me forçavam a fazer sexo com eles, vários de uma vez, 5 , 6 a 8 meninos (Luana, abril, 2019).

Em consonância com as vivências de exclusão e violência destacada pelas entrevistas, Franco (2014) aponta que há dificuldades da escola em lidar com as questões referentes às identidades de gênero e sexual, especialmente quando os sujeitos em foco são pessoas trans. Isso acaba por resultar em "modelos sociais de exclusão" por meio de ações de violência e/ ou, concomitantemente, descaso dessas ações por parte da instituição escolar.

Marcadas pelas diversas formas de discriminação e opressão vividas pelas travestis, sem família, sem escola e sem emprego, a maioria dessas pessoas são obrigadas a buscar na prostituição a sua forma de subsistência, como uma imposição social que as levam a viver as mais diversas formas de violência pelas quais são expostas profissionais do sexo, seja na relação com a sociedade e com a polícia, seja com os clientes, com a cafetinagem e colegas de trabalho (PERES, 2005, 2009). Integrando essa "maioria" descrita pelo autor, as colaboradoras desta pesquisa se pronunciaram. Luana enfatizou sobre a cafetinagem e Kely sobre a resistência dos clientes no que se refere ao uso do preservativo:

Eu acho muito dificil ser travesti, porque, quando eu comecei, todos os lugares que eu fui para tentar trabalhar, para me prostituir, tanto no Rio como aqui em Juiz de Fora, a gente além de ganhar o dinheiro dos clientes, tem travesti que trabalha como cafetina. Elas cobram uma cota da gente. Aí, se a gente não ganhar, elas nos batem e nos expulsam da cidade (Luana, abril, 2019).

Tem uns que insistem em não usar camisinha. Eu não vou abrir para pessoa e falar que eu tenho HIV. Eles insistem em fazer sem camisinha. Teve um que eu perdi por causa disso: de não abrir mão de usar camisinha. Porque eu não tenho coragem de fazer isso com as pessoas (Kely, abril, 2019).

O trecho em destaque da fala de Kely é condizente com o que Pelúcio (2007, p. 201) apontou em seu estudo:

É preciso que se considere o comportamento dos clientes, uma vez que os momentos que antecedem (assim como os posteriores) o ato sexual de fato podem ser tensos e angustiantes. Existe o medo de ser visto por conhecidos, os conflitos internos em relação à sexualidade, ao mesmo tempo em que há a excitação de se estar fazendo algo transgressor, de se realizar 
uma fantasia, de estar diante de uma sexualidade que os atrai e repugna, ao mesmo tempo. Com tudo isso, a camisinha torna-se um elemento que, muitas vezes, só é lembrado no fim do ato sexual ou quando (e se) a travesti propõe. Pegar AIDS ou qualquer outra doença sexualmente transmissivel é um medo que está subsumido ao da perda da masculinidade, este sim, o temor corriqueiro.

Porém, é importante pautar que travesti não é sinônimo de prostituta, ou seja, embora a formação do estigma social sobre as travestis tenha produzido uma tendência, no imaginário das pessoas, de associarem travestis com a prostituição, a violência e a periculosidade, a cada dia nos deparamos com travestis que exercem as mais diversas ocupações.

É possivel encontrar travestis trabalhando nos serviços públicos, nos salões de beleza e de alta costura, na prestação de serviços domésticos e, também, embora em número reduzido, com formação universitária, como é o caso de travestis que são advogados e psicólogos, além do caso de uma vereadora, em seu terceiro mandato, em pleno sertão do Piauí (PERES, 2005). Nessa vertente, considerando os obstáculos enfrentados ao longo de sua história, Kely relata sobre a forma como abandonou a prostituição e se tornou uma profissional autônoma:

Eu fiz um curso de cabeleireiro. Foi uma pessoa que eu morei com ela que começou a me ajudar, a me dar força. Pagou o curso. Esta pessoa, junto com meu pai, montou um salão pra mim. Aí, eu fui trabalhar como cabeleireira (Kely, abril, 2019).

No que se refere ao uso de drogas, dentre as literaturas relevantes na área, o trabalho de Pelúcio (2007, p. 33) pontua que um dado que salta aos olhos de quem vai a campo nos espaços de prostituição de travestis é o uso que parte delas fazem de drogas lícitas e ilícitas.

O álcool é bastante consumido por travestis, principalmente destilados como conhaque e aguardente, mais do que fermentados como cerveja, que além de mais cara, é uma bebida gelada, que não contribui para propiciar o conforto térmico que noites frias exigem.

Muitas travestis contam que o crack é a principal droga que tem causado morte e decrepitude entre elas. Outras sempre se eximindo de ficarem no grupo das "colocadas" (as que usam drogas) ou das "bandidas" (as que roubam), relatam que esse tipo de vínculo é um grande atrativo para a proximidade com o universo da marginalidade. Por isso, muitas delas recorrem às cafetinas e aos cafetões (estes últimos mais raros na prostituição de travestis) para assegurarem a ordem.

Sobre essa discussão, Kely, relatou nunca ter feito uso de drogas, associando este fato ao acolhimento familiar que teve. Por outro lado, fazendo emergir as "sinergias de vulnerabilidades" (JUNQUEIRA, 2009), Luana contounos outra versão vivenciada em sua trajetória de vida.

Senti necessidade de usar droga porque é muita revolta, muito sofrimento, muita revolta mesmo, foi uma forma de fuga, mas eu me arrependi. Eu usei de tudo: cocaína, maconha, usei crack, tomei pico na veia, injetável. Bebi bebida alcoólica, tomei álcool de posto de gasolina. Me destruí com as drogas. Hoje em dia não quero mais (Luana, abril, 2019).

Inevitavelmente, como descreve Luana, os casos mais evidentes de vulnerabilidades no sentido mais amplo têm sido os vividos por travestis e transexuais que têm, na maioria dos casos, suas possibilidades de inserção social comprometidas por estarem privadas do acolhimento afetivo em face às suas experiências de expulsões e abandonos por parte da família, da escola, do mundo social e tantas outras instituições sociais (JUNQUEIRA, 2009; PERES, 2009).

Segundo Peres (2009), o sistema de saúde tem sido ao longo das trajetórias de vidas de 
travestis brasileiras outra dessas dimensões de exclusão, contudo, neste aspecto específico, as travestis colaboradoras desta pesquisa apontam outras possibilidades de acesso aos sistemas de saúde pública, levantando indícios de certo avanço na dimensão social e humana esse serviço.

\section{Vivendo com HIV/AIDS, Sistema de Saúde e perspectivas de vida}

Quando se atrela a experiência da travestilidade ao fato de viverem com HIV/AIDS, a exclusão se torna ainda mais enfática para esses sujeitos. Diante deste contexto, Peres (2004, p. 28) aponta que: "A composição existencial na vida dessas pessoas, em rede de exclusão, favorece a efetivação do que já dominamos 'violência estrutural's, e coloca as pessoas mais intensamente disponibilizadas aos riscos e vulnerabilidades do HIV/AIDS, de forma muito perversa", aspecto manifestado nos relatos das entrevistadas.

Depois que descobri que tenho HIV, há muita apontação de dedo, um aponta para o outro. Travesti mesmo que tem HIV. Já me chamaram de aidética na esquina (Luana, abril, 2019).

No começo da AIDS eu acho que caiu muito sobre os homossexuais, caiu muito... Depois que quebrou esse tabu. Antigamente falava que era homossexual, tinha o vírus (Kely, abril, 2019).

É possivel perceber na próxima fala que a prostituição de travestis não é algo tão tranquilo como é, muitas vezes, interpretado pelo

50 conceito de violência estrutural, portanto, torna evidente que a ideia de risco individual deve ser extrapolada. O grande avanço, em termos de teorização da prevenção dos últimos anos é o processo de mudança do conceito de risco comportamental para o conceito de vulnerabilidade social. Entretanto, o desenvolvimento desses conceitos nos obriga a modificar também uma grande parte do trabalho que fazemos. Inicialmente, é preciso deixar de ter uma preocupação tão centrada na informação e na intervenção comportamental, e fomentar o que Peres (2004) define fundamentalmente de intervenção estrutural. imaginário social. Pelúcio (2007) aponta que, nos relatos de profissionais de saúde, o HIV aparece como "um detalhe" na vida dessas pessoas que já vem de um histórico tão sofrido, geralmente associado à condição de pobreza e de gênero: “Eu não fiquei triste não porque eu falei: já peguei! Eu tive um irmão que morreu com isso, meu irmão mais velho, ele foi a óbito com HIV, aí eu peguei e falei: já peguei, agora vou me cuidar." (Luana, abril, 2019).

Na história de vida de Luana, o fato de contrair o vírus HIV foi visto como uma possibilidade de conseguir o sustento através do Benefício de Prestação Continuado (BPC) e, desta forma, conseguir sair da "vida", ou da prostituição: "Eu estou morando sozinha e tenho o salário do governo, eu recebo o beneficio LOAS ${ }^{6}$, que é o que paga o meu aluguel. (...). Graças a Deus, ao HIV e o LOAS que me ajudaram muito a sair dessa vida." (Luana, abril, 2019).

Diferente de Luana, Kely teve um salão de cabeleireiro e, desta forma, teve a oportunidade de abandonar a prostituição: "Trabalhei como cabeleireira, mas, atualmente meu sustento vem da aposentadoria, não recebo nenhum benefício do governo." (Kely, abril, 2019).

Considerando as vivências que levaram as entrevistadas ao se tornarem pessoas vivendo com HIV/AIDS, interessou-nos destacar suas vivências junto ao Sistema de Saúde que as amparam quanto sua situação. Com isso, caminhamos para as últimas reflexões deste estudo.

Partindo dos apontamentos da portaria 1820 de 13 de agosto de 2009, é possível perceber avanços no que tange o atendimento

6 Lei Orgânica de Assistência Social (LOAS) é uma lei criada em 07 de dezembro de 1993 cujo objetivo é garantir o mínimo de atendimento as necessidades básicas da sociedade, que visa proteger à garantia da vida, à redução de danos e à prevenção da incidência de riscos, proteção à família, à maternidade, à infância, à adolescência e à velhice, amparo às crianças e aos adolescentes carentes a habilitação e reabilitação das pessoas com deficiência e a promoção de sua integração à vida comunitária (BRASIL, 1993). 
de pessoas trans no sistema público de saúde brasileiro. Dentre eles, nas fichas de atendimento do SUS foi disponibilizado um local para o nome social de sujeitos trans, independente do que revelam os seus documentos de identificação, sem que isso tome uma proporção desrespeitosa por parte da equipe médica e agentes de saúde (BRASIL, 2019).

Porém, vários estudos têm anunciado que nem sempre o que está escrito na Lei prevalece, se efetiva no cotidiano. Magnor Muller (2008) aponta que quando as travestis chegam e se dirigem à recepção de certos serviços públicos de saúde não são chamadas pelo nome feminino com o qual se identificam. No momento da consulta, ressoa pela sala, diante de olhares curiosos e discriminatórios, o nome que está impresso no documento de identidade. Este aspecto foi ressaltado por Valéria Romana (2008, p. 216) em um estudo realizado com travestis no Programa Saúde da Família da Lapa, Rio de Janeiro, no qual a autora destacou:

Inúmeros relatos magoados e indignados obtivemos em relação ao despreparo dos profissionais de saúde de Hospitais e ambulatórios no lidar com as travestis, tratando-as de maneira desrespeitosa, justificando absenteísmo, alta a revelia e interrupção ou abandono de tratamentos médicos.

Luana confirma em seu relato os aspectos evidenciados por Muller (2008) e Romana (2008): “Nos locais de saúde aonde eu vou eles não me chamam pelo nome social, eles me chamam pelo nome de homem mesmo. A gente já está passando mal, querendo ser atendido para ter uma melhora, a gente pega e vai, mas, eu acho horrivel." (Luana, abril, 2019). Contudo, ao se referir sobre o atendimento prestado a ela no SAE/Juiz de Fora, outra versão é relatada: "Aqui no SAE eles me chamam pelo nome de Luana." (Luana, abril, 2019).

Como já anunciado no início deste estudo, no ano de 1996, foi criado o Serviço de Assis- tência Especializada (SAE) com o intuito de proporcionar assistência a pessoas que vivem com vírus HIV e pacientes com AIDS, no sentido de contribuir para a redução de internações e gastos com tratamento, almejando uma melhor qualidade de vida aos/às usuários/as. (JUIZ DE FORA, 2009).

Desenvolvendo suas práticas de saúde, o atendimento é realizado por uma equipe multiprofissional, formada por médicos com formação em infectologia, enfermeiro, dentista, pediatra, psicólogo e assistente social. Além de profissionais de apoio, como farmacêuticos, uma vez que o SAE possui uma Unidade Dispensadora de Medicamentos antirretrovirais, se utilizando do Sistema Informatizado de Controle Logístico de Medicamentos (SICLOM) (JUIZ DE FORA, 2009).

Não diferente de Luana, Kely também sinaliza que o atendimento do SAE é diferenciado. Ambas relatam um bom acolhimento, um atendimento mais humanizado, o que significa um diferencial para que elas sintam vontade de estar e de retornar ao serviço sempre que necessário: "Eu gosto muito do serviço do SAE. Todo mundo fala que o atendimento do HU [Hospital Universitário] é muito bom, mas eu não tenho vontade de trocar, mesmo quando as pessoas falavam que no HU era mais escondido." (Kely, abril, 2019).

Nas relações interpessoais, inerentes ao exercício profissional, é a qualidade do encontro que determina sua eficiência, reconhecidamente, a empatia, entendida como a troca de sensibilidade entre médico e paciente é essencial neste encontro. Assim, na formação e na identificação do bom profissional médico, a relação médico-paciente é sempre referida como fundamental na promoção da qualidade do atendimento (PEREIRA, 2005). Esse aspecto é evidenciado pelas informantes ao se referirem ao atendimento no SAE/Juiz de Fora. 
Eu acho o Dr. [Nome do médico] muito especial, ele toda vida teve muito carinho comigo, ele brinca e tudo! Todo mundo fala que ele é bravo... Eu não posso falar nada dele! Toda vida ele foi de uma gentileza! Todo mundo que segue o tratamento, eu só vejo falar bem dele (Kely, abril, 2019).

O serviço aqui é maravilhoso! Dr. [Nome do médico] é um médico que estou com ele desde que comecei o tratamento (Luana, abril, 2019).

Considerando o que foi exposto anteriormente, importante destacar neste estudo que adesão ao tratamento é mérito dos/as profissionais do SAE, claro que motivado pelo interesse das entrevistadas. Kely recebeu o diagnóstico há 18 anos e Luana há 19 anos e ambas relatam terem uma boa qualidade de vida.

Eu não sinto nada da doença. Só tive uma vez uma pneumonia, e o que sinto mais que eu tenho enfisema pulmonar, um pouco de canseira. É por causa do enfisema, que de resto não sinto mais nada. Minha carga viral é indetectável (Kely, abril, 2019).

Não perco nenhuma consulta. Nossa... Eu acho maravilhoso. E o atendimento do pessoal aqui comigo? (Luana, abril, 2019).

Mediante o que foi explicitado nesta seção, fica em evidência que o estigma e a discriminação têm sido apontados como importantes obstáculos ao acesso desse segmento social aos serviços de prevenção e cuidado. Mas é importante ressaltar que existem serviços, como o SAE de Juiz de Fora, que oferece uma assistência de inclusão, aspecto ponderado na perspectiva das entrevistadas.

Com isso, o SAE parece se esforçar para cumprir as medidas descritas no Plano de Enfrentamento da AIDS entre Gays, Homens que fazem Sexo com Homens (HSH) e Travestis (BRASIL, 2007). Da mesma forma, tenta garantir o mínimo de atendimento às necessidades básicas da sociedade nas quais a proteção e garantia à vida são especiais como descrito desde 1993 na Lei Orgânica de Assistência Social (LOAS) (BRASIL, 1993).

\section{Considerações Finais}

O objetivo deste estudo foi de conhecer as histórias de vida de travestis vivendo com HIV/AIDS acompanhadas pelo serviço de atendimento de saúde do SAE/Juiz de Fora. Para trazer parte das vivências deste público que historicamente esteve e ainda permanece à margem da sociedade. Utilizamos como metodologia a história oral temática, o que nos permitiu entender os processos de construção de suas identidades de gênero e como esse processo se deu mediante as relações familiares, escolares, profissionais, dentre outras.

No decorrer da análise foi possivel perceber que por diversos momentos as histórias de Kely e Luana possuem determinantes parecidos como o processo de descoberta como travestis, as mudanças corporais e relação com a prostituição. Sobre as diferenças, identificamos as formas de aceitação ou rejeição da família, o uso de drogas e as possibilidades de reconstrução de suas histórias pelo viés da profissionalização e/ou a inserção no Sistema de Saúde público em razão do HIV/AIDS.

Assim como outros estudos na área, evidenciamos o quanto essa população sofre com os diferentes tipos de preconceitos, seja pelo trabalho como prostituta, seja por viver com HIV/AIDS ou pelo fato de serem travestis. Por outro lado, o estudo nos permite afirmar o quanto o serviço de saúde com uma equipe motivada em trabalhar com um olhar mais humano faz a diferença para os/as usuário/as em acompanhamento.

Como descrito no relato das entrevistadas, o SAE/Juiz de Fora emerge como um espaço de respeito às diferenças e à diversidade humana. 


\section{Referências}

BENEDETTI, Marcos. Toda Feita: o corpo e o gênero das travestis. Rio de Janeiro: Garamond, 2005.

BENTO, Berenice. A Reinvenção do Corpo: sexualidade e gênero na experiência transexual. Rio de Janeiro: Garamond, 2006.

BRASIL, Ministério da Saúde. Lei Orgânica da Assistência Social (LOAS). Lei no 8.742 , de 7 de dezembro de 1993. Disponivel em http://www.planalto.gov.br/ ccivil_03/LEIS/L8742compilado.htm. Acesso em: 10 de jul. 2019.

BRASIL, Ministério da Saúde. A Luta pelo Direito à Saúde de Lésbicas, Gays, Bissexuais, Travestis e Transexuais. Política Nacional de Saúde Integral de Lésbicas, Gays, Bissexuais, Travestis e Transexuais, 2013. Disponivel em: http://bvsms.saude.gov.br/ bvs/publicacoes/politica_nacional_saude_lesbicas_gays.pdf. Acessado em: 28 maio de 2019.

BRASIL, Ministério da Saúde. Raça, Gênero e Sexualidade em Perspectivas Discursivas: teorias e análises. Hélton Diego Lau, Éderson Luís Silveira - organizador. São Paulo: Pimenta Cultural, 2019.

BRASIL, Ministério da Saúde. Plano Nacional de Enfrentamento da Epidemia de AIDS e das DST entre Gays, HSH e Travestis. Brasília: Ministério da Saúde: 2007.

FERREIRA JUNIOR, Sérgio; FRANCISCO, Priscila Maria S. B.; NOGUEIRA, Péricles A. Perfil de travestis e transgêneros: tuberculose e HIV/Aids na cidade de São Paulo. Revista Panam Salud Publica, São Paulo, v. 40, n. 6, p. 4010-417, 2016. Disponível em https:// www.scielosp.org/pdf/rpsp/2016.v40n6/410-417/pt. Acesso em: 24 jun. 2019.

FRANCO, Neil. Professoras trans brasileiras: ressignificações de gênero e de sexualidades no contexto escolar. 268f. Tese (Doutorado em Educação). Programa de Pós-Graduação em Educação da Universidade Federal de Uberlândia: 2014. Disponivel em https:// repositorio.ufu.br/bitstream/123456789/13671/1/ ProfessorasTransBrasileiras.pdf. Acesso em: 24 jun. 2019.

JUIZ DE FORA. Programa Municipal DST/AIDS em Juiz de Fora/MG. SSSDA/PJF, 2009. Disponivel em https://www.pjf.mg.gov.br/secretarias/ss/aids_dst/ artigos.php. Acesso em: 24 jun. 2019.

JUNQUEIRA, Rogério Diniz. Homofobia nas escolas: um problema de todos. In: JUNQUEIRA, Rogério Diniz. Diversidade sexual na educação: problematizações sobre a homofobia nas escolas. Brasília: Ministério da Educação, Secretaria de Educação Continuada, Alfabetização e Diversidade, UNESCO, 2009. p. 13-52.

KULICK, Don. Travesti: prostituição, sexo, gênero e cultura no Brasil. Tradução de Cesar Cordon. Rio de Janeiro: Fiocruz, 2008.

LOURO, Guacira. Gênero, sexualidade e educação: uma perspectiva pós estruturalista. Petrópolis, Rio de Janeiro: Vozes, 1997.

MEIHY, José Carlos S. B; HOLANDA, Fabíola. História oral: como fazer, como pensar. 2. ed. rev. e aum. São Paulo: Contexto, 2010.

MISKOLCl, Richard. Teoria Queer: um aprendizado pelas diferenças. Belo Horizonte: Autêntica Editora: UFOP - Universidade de Ouro Preto, 2012.

MONTEIRO, Simone; BRIGADEIRO, Mauro; BARBOSA, Regina M. Saúde e Direito da População Trans. Cadernos de Saúde Pública, Rio de Janeiro, v. 35, n. 4, p. 1-4, 2019. Disponivel em http://www.scielo.br/ pdf/csp/v35n4/1678-4464-csp-35-04-e00047119.pdf. Acesso em: 10 jun. 2019.

MULLER, Magnor. Desigualdades no SUS: o caso de atendimento às travestis é "babado!". Cadernos EBAPE, Brasília, v. 6 n. 2, 2008. Disponível em http:// bibliotecadigital.fgv.br/ojs/index.php/cadernosebape/article/view/5067/3801. Acesso em 06 jul. 2019.

NOGUEIRA, Francisco. "Trabalhadas no feminino": um estudo sobre corpo, desejo e prostituição travesti em Fortaleza. Revista Latinoamericana de Estudios sobre Cuerpos, Emociones y Sociedad, Buenos Aires, ano 4, n. 8, p. 55-67, abr./jul. 2012. Disponivel em http://www.relaces.com.ar/index. $\mathrm{php/relaces/article/viewArticle/171.} \mathrm{Acesso} \mathrm{em:} 08$ jun. 2019. 
PELÚCIO, Larissa. Nos nervos, na carne, na pele: uma etnografia sobre prostituição travesti e o modelo preventivo de Aids. 2007. 312p. Tese (Doutorado em Ciências Sociais) - Centro de Educação e Ciências Humanas, Universidade Federal São Carlos. São Carlos: 2007. Disponível em https://repositorio.ufscar.br/handle/ufscar/1399?show=full. Acesso em: 29 jun. 2019.

PEREIRA, Maria das Graças. A relação médico-paciente em Rio Branco/AC sob a ótica dos pacientes. Revista Associação Médico Brasileira, Rio Branco, v. 51, n. 3, p. 153-7, 2005. Disponível em: http://www. scielo.br/pdf/\%0D/ramb/v51n3/a16v51n3. Acesso em: 03 de jul. 2019.

PERES, William. Cenas de exclusões anunciadas: travestis, transexuais, transgêneros e a escola brasileira. In: JUNQUEIRA, Rogério Diniz. Diversidade sexual na educação: problematizações sobre a homofobia nas escolas. Brasília: Ministério da Educação, Secretaria de Educação Continuada, Alfabetização e Diversidade, UNESCO, 2009. p. 235-264.
PERES, William.Violência estrutural e AIDS na comunidade travesti brasileira. Revista Psicologia da UNESP, São Paulo, v. 3, n. 1, p. 21-31, 2004, Disponível em: http://seer.assis.unesp.br/index.php/psicologia/article/view/991. Acessado em: 29 maio 2019.

ROMANA, Valéria. As travestis no Programa Saúde da Família da Lapa. Saúde Soc. São Paulo, São Paulo, v. 17, n. 2, p. 211-219, 2008. Disponível em: https:// www.scielosp.org/pdf/sausoc/2008.v17n2/211-219/ pt. Acesso em: 11 jul. 2019.

SOUZA, Martha H.; MALVASI, Paulo; SIGNORELLI, Mar$\cos$ C.; PEREIRA, Pedro P. G. Violência e sofrimento social no itinerário de travestis de Santa Maria, Rio Grande do Sul, Brasil. Caderno Saúde Pública. Rio de Janeiro, v. 31, n. 4, p. 767-776, abr. 2015. Disponivel em: https://www.scielosp.org/pdf/csp/2015. v31n4/767-776/pt. Acesso em: 03 jul. 2019.

Recebido em: 25.08.2019

Aprovado em: 20.01.2020

Angra Dias da Silva Tagliate é Graduada em Serviço Social e especialista em Relações de gênero e sexualidades em perspectivas interdisciplinares pela Universidade Federal de Juiz de Fora. Atua no Departamento DST/AIDS de Juiz de Fora. E-mail: angratagliate@hotmail.com

Neil Franco é graduado em Licenciatura Plena em Educação Física, Mestre e Doutor em Educação pela Universidade Federal de Uberlândia. Atua como docente na Faculdade de Educação Física e Desportos e no Programa de Pós-Graduação em Educação da Universidade Federal de Juiz de Fora. É líder do Grupo de Estudos e Pesquisa: Corpo, Culturas e Diferença. E-mail: neilfranco010@hotmail.com 